\title{
Some observations on the breakage of ultrasonic files driven piezoelectrically
}

Ahmad M, Roy RA. Some observations on the breakage of ultrasonic files driven piezoelectrically. Endod Dent Traumatol 1994; 10: 71-76. (C) Munksgaard, 1994.

Abstract - The incidence of breakage of Piezon-Master ultrasonic $\mathrm{K}$ files were evaluated. Three groups of unused files were subjected to three treatments, namely; free vibration in air without irrigation, free vibration in root canal while minimizing contact with the wall of canal in the presence of irrigation and light filing in root canal with free flow of irrigation. Cavitation produced by files in contact and free of contact with a glass surface was examined in order to observe the relationship between cavitation defects and breakage. In addition, the fractured and unfractured files were examined under a scanning electron microscope for the presence of cavitation pits. The results indicated that more files broke in air. In water, a higher incidence of breakage occurred when files were allowed to freely vibrate while no breakage occurred when the files were used in filing. All files generated cavitation which resulted in pitting of their surfaces. However, it was considered unlikely that the pits contributed to fracture. Fatigue cracks which could be the result of the manufacturing process were observed at some of the corners of the cross sections of the fractured files and could be the main contributory factor to fracture.

\section{Majinah Ahmad, Ronald A. Roy}

Department of Conservative Dentistry, University of Malaya, Kuala Lumpur, Malaysia, Applied Physics Laboratory, University of Washington, Seattle, USA

Key words: endodontic therapy; ultrasonic instrumentation; endodontic file fracture.

Majinah Ahmad, Dept. of Conservative Dentistry, Faculty of Dentistry, University of Malaya, 59100 Kuala Lumpur, Malaysia.

Accepted July 8, 1993
Instrument breakage is frequently encountered in clinical practice and is a serious mishap. This is because when a file breaks and get lodged in the canal of a tooth, the success rate of root canal treatment could be jeopardized (1). Such breakages have been attributed to either clinical mishandling $(2,3)$ or manufacturing flaws and reduced strength due to instrument design $(1,4-6)$.

The ultrasonic technique of root canal preparation employs a file that vibrates when the mechanical energy from the transducer is transferred to it. It is thought that the vibrations inherent in such a file can increase the likelihood of breakage. However, studies carried out using the Cavi-Endo unit revealed that the breakage incidence with the CaviEndo file was relatively low $(7,8)$.

Recently several additions to the ultrasonic endodontic armamentarium were made. They differ from the Cavi-Endo in terms of the frequency of the generator and the type of transducer employed. These newer units employ a higher frequency generator and a piezoelectric transducer which is more powerful than the magnetostrictive type originally employed by the Cavi-Endo (9). A survey of the literature revealed that no studies have been carried out with regards to the life-span of the files powered by the piezoelectric transducers. In view of this, the present study was undertaken to evaluate the breakage incidence of the files driven by a piezoelectric unit.

The ultrasonic file has been shown to cause cavitation in the irrigating solution (10). Cavitation is an effective mechanism for the local application of highly concentrated energy. The growth and subsequent collapse of a bubble gives rise to shock waves and imploding jets that can cause severe damage to surrounding areas (11). The microerosion of solid surfaces suspended in a cavitating liquid is a 
well-established phenomenon. Cavitation damage on metal has been reported by several authors (12, 13). Such damage started with plastic deformation, followed by work hardening, fatigue and eventual failure of areas on the specimen. In view of the possibility of a similar phenomenon occurring with the ultrasonic file, the present study also evaluated the cavitational phenomenon of the file and its effect on the incidence of breakage.

\section{Material and methods}

The ultrasonic unit investigated was the Piezon Master 400 (Electro-Medical System, Switzerland) which has a driven frequency of $28 \mathrm{kHz}$ and employs $\mathrm{K}$ files of sizes 15,20, 25, 30 and 35 . The file holder which was termed by the manufacturer as the endo-chuck was of the 120 degree type. The incidence of fracture of the file was of the 120 degree type. The incidence of fracture of the file was evaluated by subjecting a total of 10 files of each size to various treatments. The samples were taken from five batches of files. The treatments were as follows: 1) free vibration in air without irrigation; 2) free vibration in root canal with minimal contact and with irrigation flowing; 3) light filing in a root canal with free flow of irrigation.

These treatments were carried out in order to simulate the conditions that the file would be subjected to in the clinic. The file investigated was attached to the file holder so that the part of the file that freely vibrated (measured from the apical end to the position where it was clamped to the endochuck) was $22 \mathrm{~mm}$ long. This was the length measured when the file was inserted fully into the endochuck and is the length recommended for clinical use by the manufacturer. The power setting was set to the lowest value on the control dial and each file was vibrated for $5 \mathrm{~min}$. Following the experiment, each file was examined for breakage.

\section{Displacement amplitude of files}

In order to see the relationship between file displacement amplitude and the occurrence of fracture, the tip displacement amplitudes of three files of the same size were measured. For this measurement, the file was positioned horizontally so that the tip could be observed with a light microscope (magnification $\times 100)$. When the file vibrated, a shiny spot of reflected light on the tip of the file could be seen moving as a thin line; half of the length of this line gave the value of the displacement amplitude. During measurements, many files broke. For those files which broke, measurements were repeated so that the average displacement amplitude of three files could be determined.

\section{Microscopic observations of files' surfaces}

All files investigated were examined using a scanning electron microscope for cavitation pits and microcracks and photographs were taken. The locations of the breakage sites were also determined. This was done by comparing the length of the broken file with a new unused file. In addition, the position of breakage in relation to the nodal points were determined. The nodal points had been previously determined and reported elsewhere (9).

\section{Measurements of cavitation}

In order to see the relationship of cavitation pitting to breakage, an experiment was conducted to detect cavitation from the files. This was later correlated to the incidene of breakage. A method to detect cavitation from the vibrating files was to detect the amount of light emitted when the cavitating bubbles imploded. When it occurred on a surface, cavitation produced pitting of the surface. The experimental arrangement used to detect light emission from cavitation is shown in Fig. 1. A simulated root canal was constructed from $1.09 \mathrm{~mm}$ (internal diameter), $12 \mathrm{~mm}$ long glass capillary tube sealed at one end. The file under observation was inserted into this tube in such a way as to minimize contact with the side walls when it vibrated. A group of three files, of sizes 15,20, 25, 30 and 35 were investigated for cavitation.

The experiment was repeated with the file purposely loaded by the side of the canal with the irrigation flowing. This condition was achieved through the application of a steady transverse force using the ring-stand clamp as an actuator. Similar number and size of files were investigated. Due to experimental constraints, filing motions as carried out in the first experiment was not performed. The

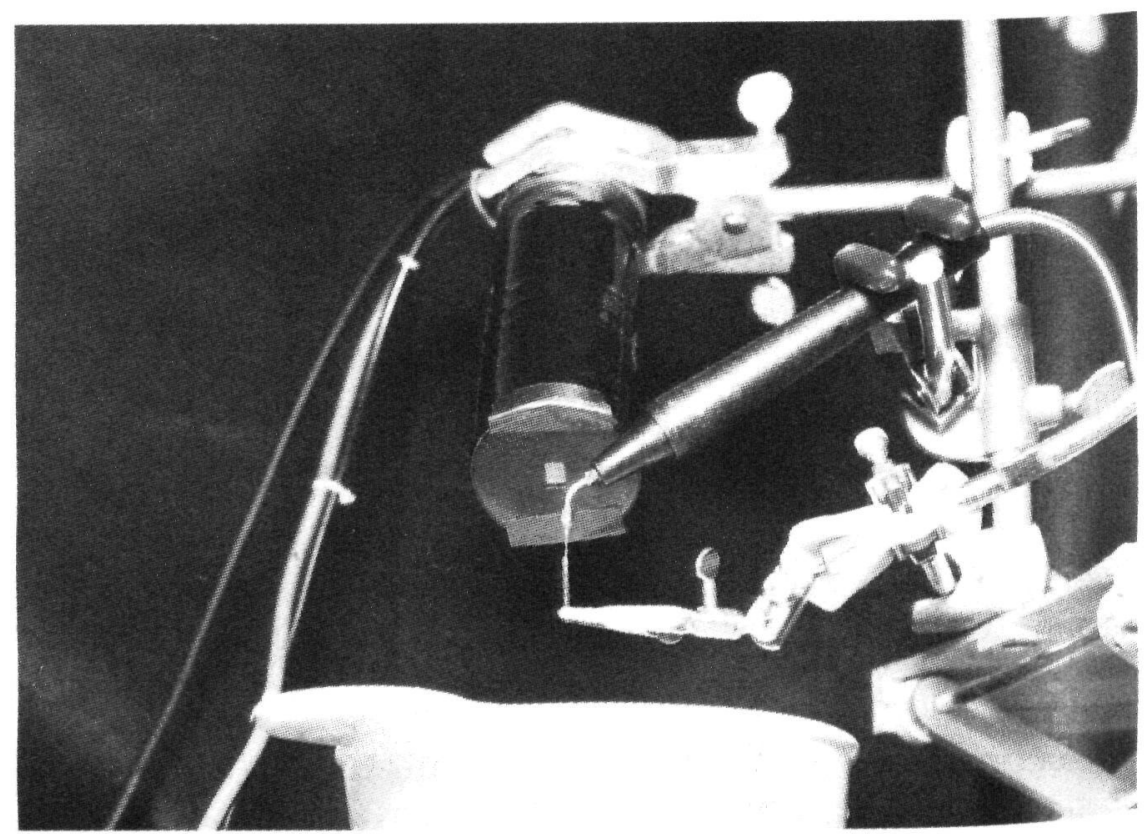

Fig. 1. Photo multiplier system to detect cavitation. 
onset of cavitation was shown by the production of light. The level of light emission was very low; therefore, experiments were run in a light-tight room using the single-photon-counting apparatus shown in Fig. 1. A photomultiplier tube was used to detect the light emission. The tube was directed toward the simulated canal. The output of the tube was fed into the single-photon-counting unit. Count rates in kilocounts per second ( $\mathrm{kcps}$ ) were displayed on the readout and recorded manually.

Some of the files broke after $10 \mathrm{~s}$ of free vibration under water. These files as well as all the other files that did not break were examined for cavitation pits using scanning electron microscope.

\section{Results}

Free vibration in air without irrigation

The results are tabulated in Table 1. No fracture occurred with sizes 15 and 35 files. Size 25 files exhibited the highest percentage of breakage $(70 \%)$, while size 20 exhibited $60 \%$ incidence of breakage. Forty percent of size 30 files that were examined exhibited breakage.

\section{Free vibration under water in root canal}

With the exception of size 20, 25 and 30 files, fracture was eliminated when files sizes 15 and 35 vibrated under water (Table 1).

Filing in root canal with free flow of irrigation

No incidence of fracture was observed in all the files examined when used for filing (Table 1).

\section{Displacement amplitude and fracture incidence}

In order to see the relationship between displacement amplitude and fracture, the values of displacement amplitude and the incidence of fracture for each file size was tabulated (Table 2). Although a direct comparison was complicated by the fact that different size files were used, there was no correlation between displacement amplitude and the incidence of fracture. For example, size 15 file exhibited the highest amplitude yet no fracture occurred.

\section{SEM observations of files}

The files that broke exhibited breakage at the tip. On average, it was observed that breakage occurred at approximately $2.5 \mathrm{~mm}$ from the tip immediately after the first node (Table 3 ).

All fractured surfaces exhibited brittle failure. Each cross-section had four sides which were of unequal lengths (Fig. 2). In addition, the sides ap-
Table 1. Incidence of fracture of files of sizes 15, 20, 25, 30 and 35 at minimum power setting.

\begin{tabular}{|c|c|c|c|c|c|}
\hline \multirow[b]{2}{*}{ Treatment } & \multicolumn{5}{|c|}{ Fracture Incidence $n=10$} \\
\hline & $\# 15$ & $\# 20$ & $\# 25$ & $\# 30$ & $\# 35$ \\
\hline In air & - & $6(60 \%)$ & $7(70 \%)$ & $4(40 \%)$ & - \\
\hline $\begin{array}{l}\text { In root canal free of } \\
\text { contact, with irrigation }\end{array}$ & - & $3(30 \%)$ & $7(70 \%)$ & $7(70 \%)$ & - \\
\hline $\begin{array}{l}\text { Light filing in root canal, } \\
\text { with irrigation }\end{array}$ & - & - & - & - & - \\
\hline
\end{tabular}

$-=$ no fracture occurred

Table 2. Incidence of fracture and mean displacement amplitude of files sizes $15,20,25,30$ and 35 at minimum power setting vibrated in air.

\begin{tabular}{lcccrrr}
\hline & \multicolumn{2}{c}{ Fracture } & & \multicolumn{2}{c}{$\begin{array}{c}\text { Displacement }(\mu \mathrm{m}) \\
(\mathrm{n}=15)\end{array}$} \\
\cline { 2 - 3 } \cline { 5 - 6 } File size & sample & incidence & & mean & $(\mathrm{SD})$ \\
\hline 15 & 10 & $0(0 \%)$ & & 100.8 & $(10.8)$ \\
20 & 10 & $6(60 \%)$ & & 129.0 & $(9.5)$ \\
25 & 10 & $7(70 \%)$ & & 83.0 & $(4.1)$ \\
30 & 10 & $4(40 \%)$ & & 56.7 & $(16.6)$ \\
35 & 10 & $0(0 \%)$ & & 30.2 & $(5.0)$ \\
\hline
\end{tabular}

Table 3. Mean position of fracture measured from apical tip of the file $(\mathrm{mm})$ for files which fractured driven at power setting 1 in root canal in the presence of water.

\begin{tabular}{ccc}
\hline & \multicolumn{2}{c}{ Fracture } \\
\cline { 2 - 3 } Size & sample & position \\
\hline 20 & 3 & $2.42(0.382)$ \\
25 & 7 & $2.93(0.472)$ \\
30 & 7 & $2.61(0.476)$ \\
\hline
\end{tabular}

peared to be distorted. Fatigue cracks were observed at the corners of the cross-sections of some of the samples.

All the files examined for cavitation exhibited pitting on their surfaces (Figs. 3a, b). The pitting was present in both fractured and unfractured files (Table 4). Unused files which were not subjected to the cavitation test did not exhibit such pitting (Fig. 3c). Most of the pits appeared at the coronal one third of the file and they were irregularly distributed. The size and depth of the pits varied. The largest measured $10 \mu \mathrm{m}$ in length, $5 \mu \mathrm{m}$ in diameter and $5 \mu \mathrm{m}$ in depth. The smallest pit was $5 \mu \mathrm{m}$ in length, $3 \mu \mathrm{m}$ in diameter and $3 \mu \mathrm{m}$ in depth. The sides and base of each pit appeared smooth.

\section{Measurements of cavitation}

Figs. $4 \mathrm{a}-\mathrm{e}$ show the light output for files sizes 15 , 20, 25, 30, 35 respectively. Light emission indicative 


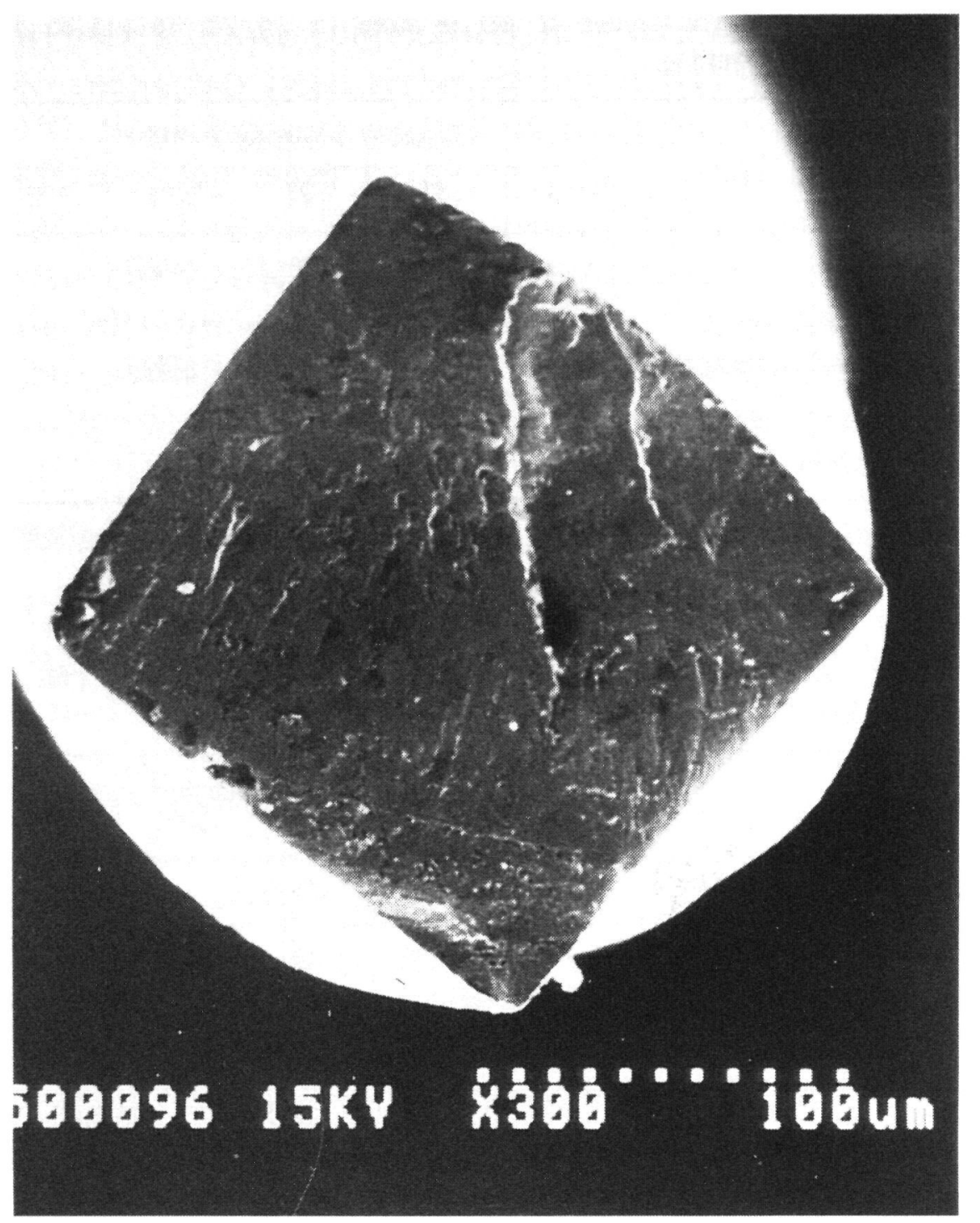

Fig. 2. A typical example of the cross-sectional surface of the file showing brittle failure.

of transient cavitation was readily observed from all the files. In all the files, there appeared to be a delay in the onset of cavitation production. Files that vibrated freely in the simulated root canal appeared to produce more cavitation than file that was in contact with the glass wall.

\section{Discussion}

It was apparent from the results of the study, that when vibrated in air, files of sizes 20, 25 and 30 broke most frequently. Files of size 25 and 30 , vibrated for a few seconds before they broke while those of size 20 broke immediately after the foot switch was engaged. The breakage occurred at the lowest setting. This indicated that these files were weak and lacked the strength to withstand the ultrasonic vibrations.

It was observed that some breakage was prevented when files vibrated in water. Furthermore, breakage appeared to be totally eliminated when the files were used in filing motions. From these results, it appeared that both water and contact with root canal wall offered resistance (damping) to the file oscillation and this could have reduced the amplitude, consequently preventing breakage. In view of this, it is recommended that to avoid breakage the file should only be allowed to vibrate in contact with the root canal in the presence of

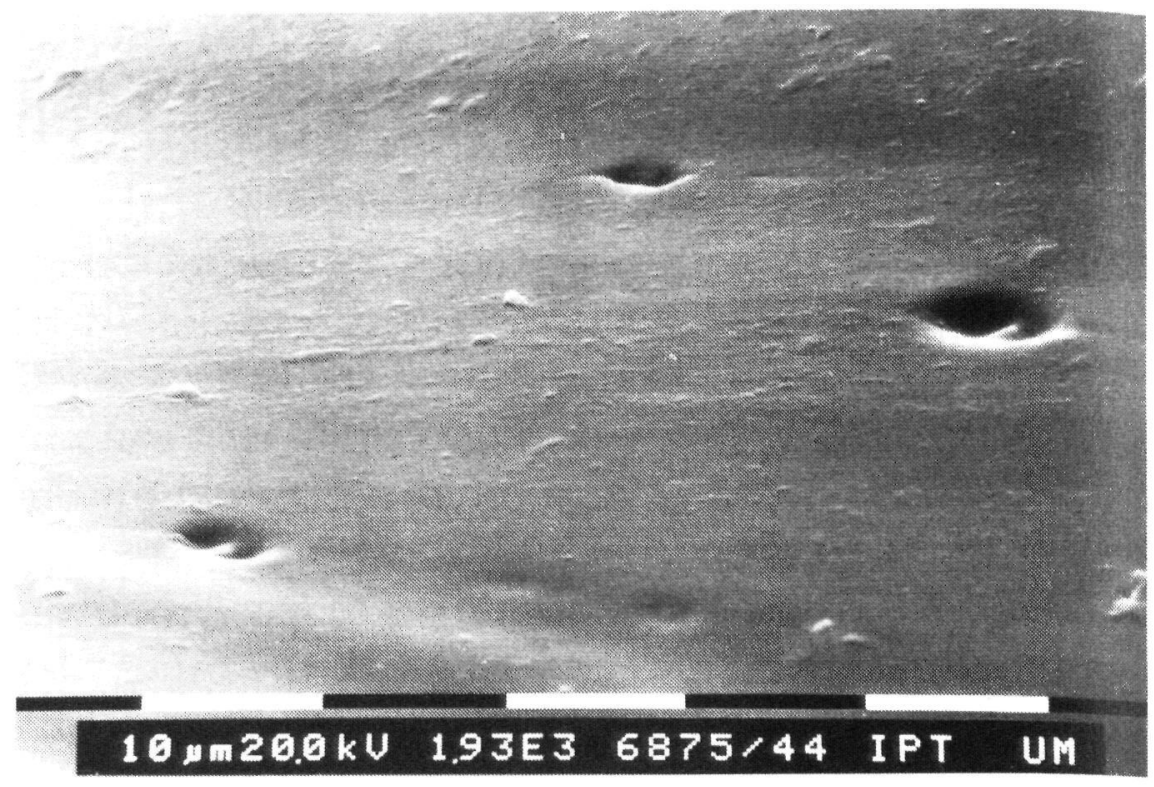

Fig. 3a. A typical example of pitting produced by cavitation implosion $(\times 190)$.

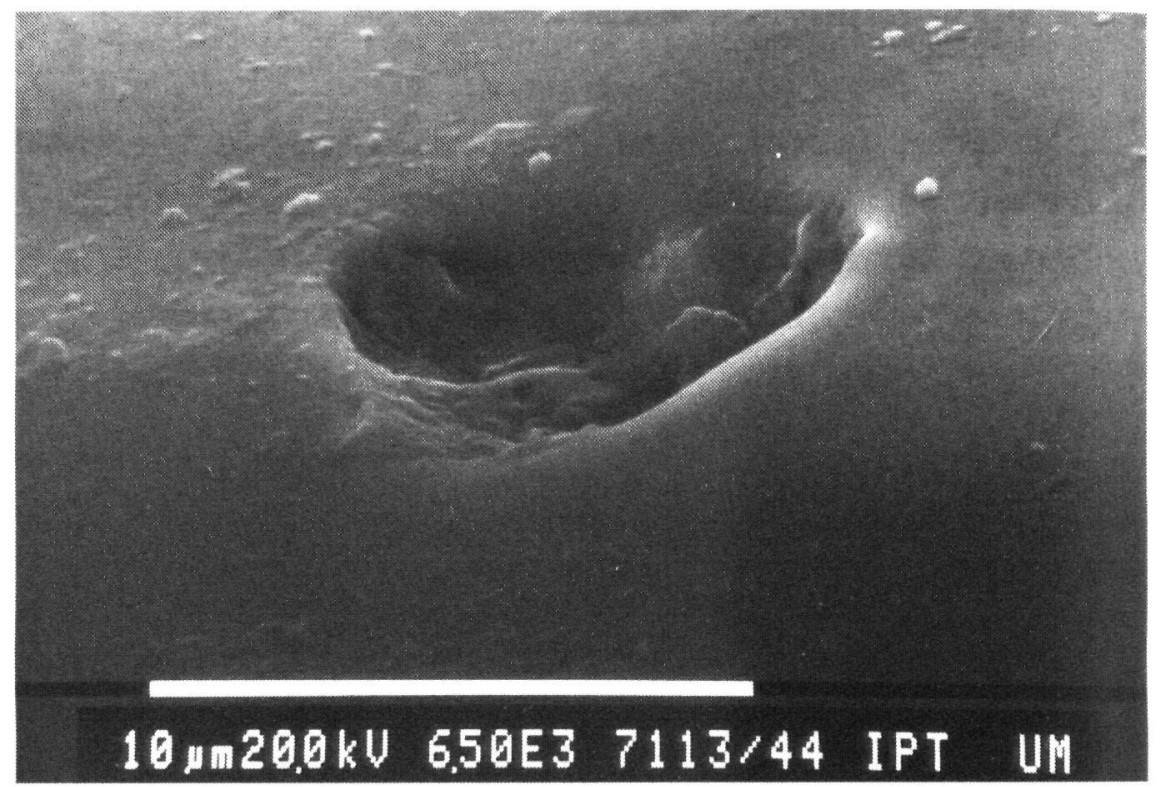

Fig. 3b. Close-up view of a cavitation pit $(\times 650)$.

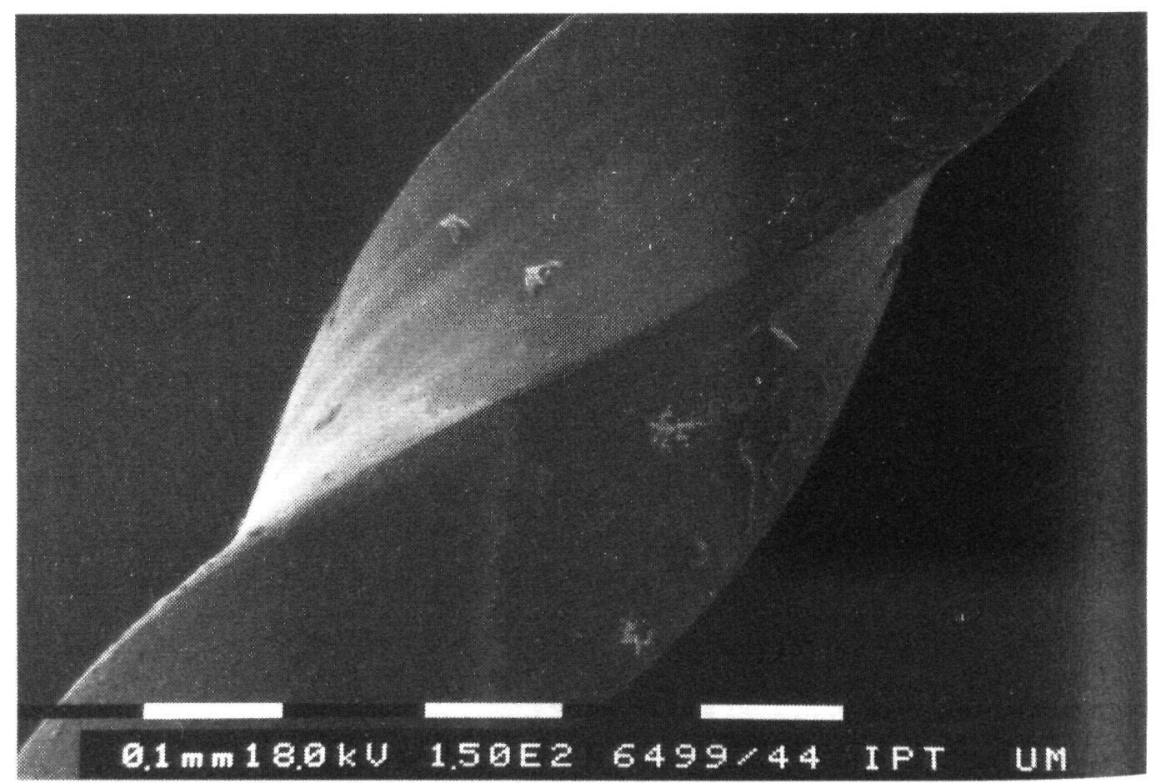

Fig. 3c. Absence of pitting on a new, unused file $(\times 150)$.

irrigation. Should the operator wish to examine the vibrating file before inserting into the root canal, then the file should only be allowed to vibrate in the presence of water. This can be done by engaging the switch for irrigation before the switch for vibrating the file is switched on.

With the exception of size 15, there appeared to be a relationship between breakage incidence and the displacement amplitude. Files with larger ampli- 
Table 4. Incidence of cavitation pits and their mean position in files which exhibited cavitation.

\begin{tabular}{|c|c|c|c|c|c|}
\hline \multirow[b]{2}{*}{$\begin{array}{l}\text { File } \\
\text { Size }\end{array}$} & \multirow{2}{*}{$\begin{array}{c}\text { Sample } \\
\text { exhibiting } \\
\text { cavitation }\end{array}$} & \multirow{2}{*}{$\begin{array}{l}\text { Sample } \\
\text { with } \\
\text { pits }\end{array}$} & \multicolumn{3}{|c|}{ Position from apical end (mm) } \\
\hline & & & $\begin{array}{c}\text { First } \\
\text { antiNode }\end{array}$ & $\begin{array}{c}\text { Second } \\
\text { antiNode }\end{array}$ & $\begin{array}{c}\text { Third } \\
\text { antiNode }\end{array}$ \\
\hline 20 & 6 & 6 & $\begin{array}{c}0.644^{+} \\
(0.220)\end{array}$ & $\begin{array}{c}4.117 \\
(0.438)\end{array}$ & $\begin{array}{c}9.308 \\
(0.480)\end{array}$ \\
\hline 25 & 6 & 3 & - & $\begin{array}{c}3.865 \\
(0.304)\end{array}$ & $\begin{array}{c}7.554 \\
(0.304)\end{array}$ \\
\hline 30 & 6 & 3 & - & $\begin{array}{c}4.567 \\
(0.304)\end{array}$ & $\begin{array}{c}7.905 \\
(0.527)\end{array}$ \\
\hline
\end{tabular}

Figures in bracket denote standard deviation

+ Excluding one sample which fractured

- No pitting/apical end lost following fracture

tudes, fractured more frequently than those with lower amplitudes.

The fractures were located at the apical end at about $2-3 \mathrm{~mm}$ away from the tip, namely at the nodes. The nodes were stress concentration areas and the alternating stresses acting when the file vibrate, could have opened up existing cracks produced during its manufacture.

Observations of the cross-sections of the fractured ends of the files, revealed that the sides of the file's cross-section were not equal in length, they appeared distorted. Such distortions could have been the result of the twisting process imparted during manufacture. The apices of the corners must have been severely deformed and acted as points for the initiation of fatigue cracks when the file vibrated.

Transient cavitation was readily observed in all the files investigated provided wall contact was avoided. There appeared to be a delay in the onset of cavitation. This delay could be due to some gradual change in the characteristics of the cavitation nuclei that gave rise to transient cavitation. When the file was allowed to contact the wall of the root canal, cavitation was greatly reduced. It might be possible that contact on the wall impeded the movement of the file, consequently reducing cavitation.

The phenomenon of transient cavitation is characterized by the implosion of cavitation bubbles. It is well-known that when such implosion occurs near the vicinity of a hard surface, for example a metal, pitting of the latter can result. In the present study some of the files examined for cavitation exhibited pitting on their surfaces. The pitting was most likely the result of the cavitation bubble imploding on the surface of the file. The position of the pitting appeared to be related to the antinode position on the file which is the site to which cavitation bubbles would normally migrate.

It appeared unlikely that pitting from cavitation contributed to fracture. Fracture was observed to

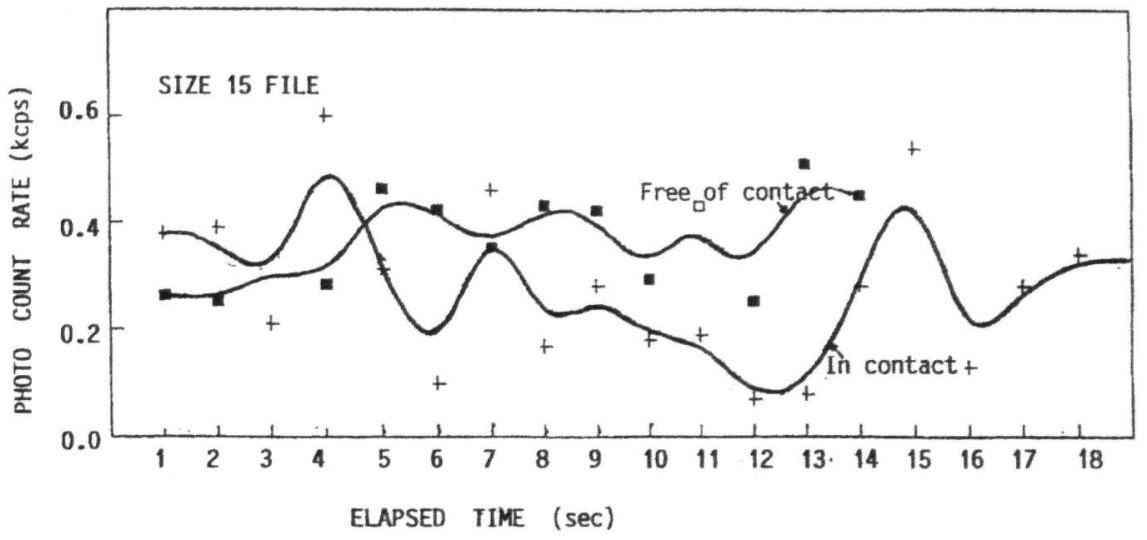

Fig. 4a. Light emission from a size 15 file relatively free of contact and in contact with the simulated canal wall.

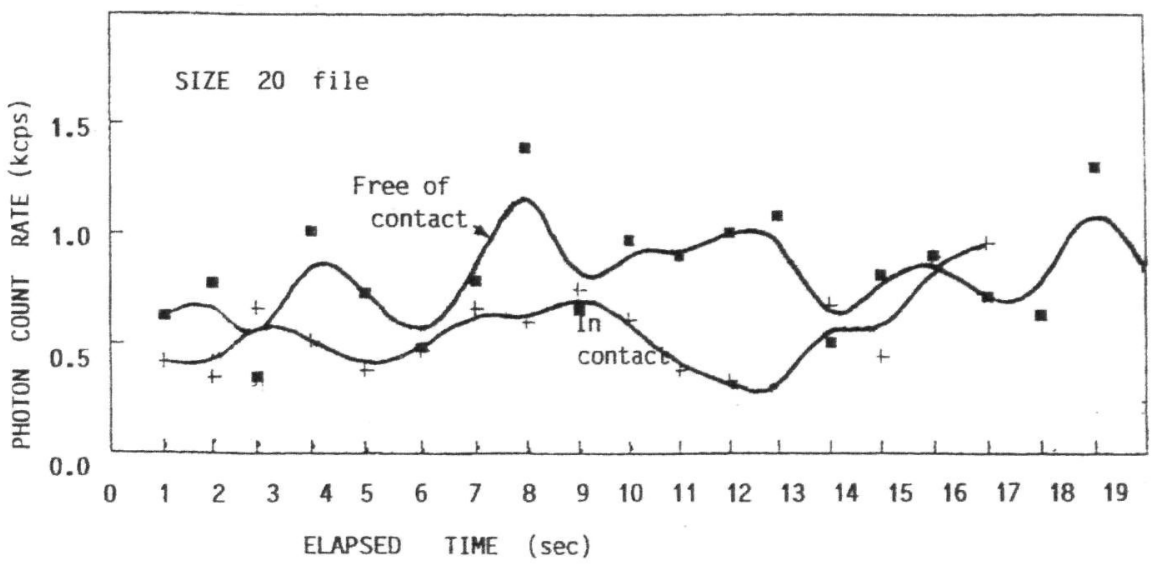

Fig. 4b. Light emission from a size 20 file relatively free of contact and in contact with the simulated canal wall.

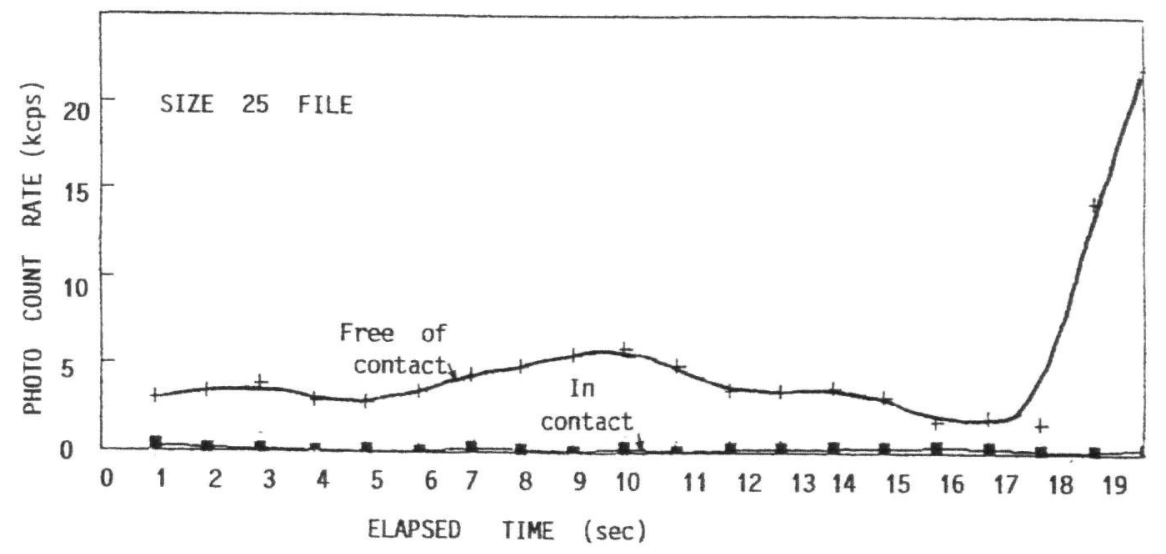

Fig. 4c. Light emission from a size 25 file relatively free of contact and in contact with the simulated canal wall.

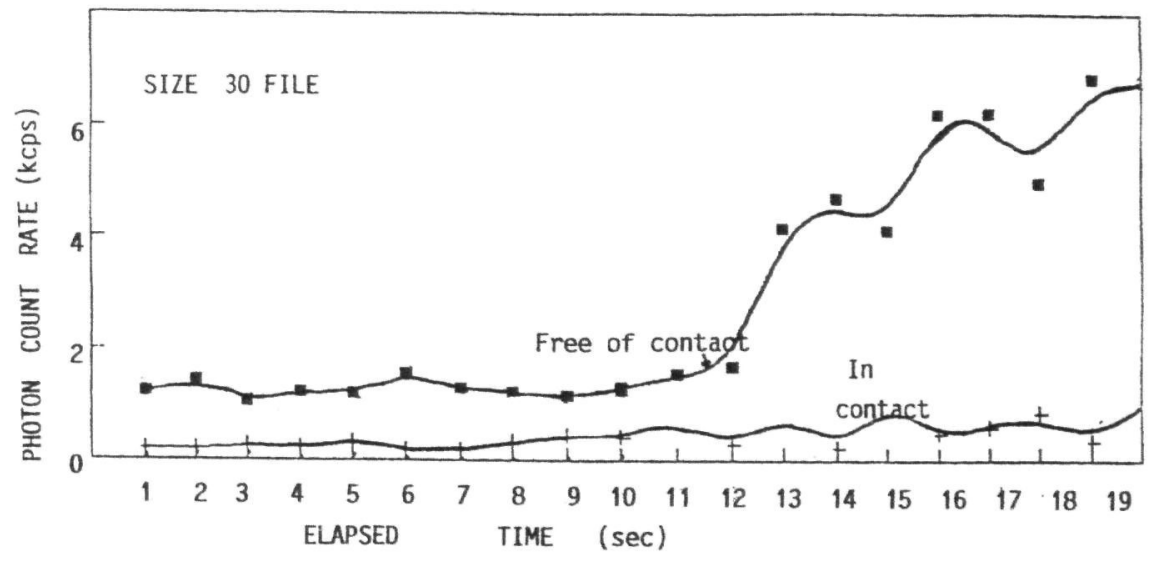

Fig. 4d. Light emission from a size 30 file relatively free of contact and in contact with the simulated canal wall.

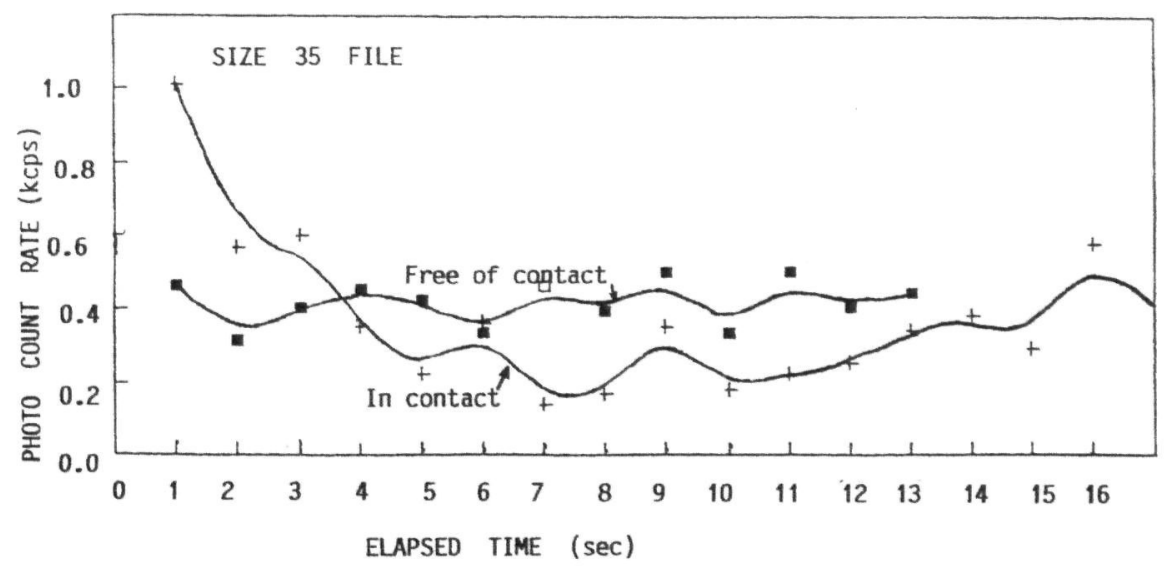

Fig. 4e. Light emission from a size 35 file relatively free of contact and in contact with the simulated canal wall. 


\section{Ahmad \& Roy}

have occurred at the nodal positions while the positions of most of the pitting appeared to be related to the antinodal points.

\section{Conclusion}

The Piezon-Master K files exhibited high incidence of fracture when vibrated freely in air. Fracture was less likely to occur when the file was used in filing in the root canal with the irrigation flowing. All files generated cavitation but only some exhibited pitting on their surfaces. Howevr, it appeared unlikely that the pits contributed to fracture.

Acknowledgements - This study was funded by a grant from the Electro-Medical System, Switzerland, grant No: 30332. We would like to thank Miss Marni Safar, for the technical assistance rendered.

\section{References}

1. Heuer MA. Instruments and materials. In: Cohen S, Burns RC eds. Pathways of the pulp. St. Louis: Mosby 1984; 427-65.

2. Chernick LB, Jacobs JJ, Lautenschlarger eP, Heuer MA. Torsional failure of endodontic files. I Endod 1970; 2: 94-7.
3. Lautenschlarger ep, Jacobs JJ, Marshall GW, Heuer MA. Brittle and ductile torsional failures of endodontic instruments. J Endod 1978; 3: 175-8.

4. Roth WC, Gouch RW, Grandish RA, Walker WA. A study of the strength of endodontic files: potential for torsional breakage and relative flexibility. 7 Endod 1983; 9: 228-32.

5. Mueller HJ, Suchak AJ, Stanford WB, Stanford JW, STANFORd SK. Comparison in some root canal instruments in bending and torsion to newly formed or drafted specifications. J Endod 1984; 10: 182-7.

6. Bolger WL, Gough RW, Foster CD. A comparison for potential for breakage: the Burns unifile versus Hedstroem file. F Endod 1985; 11: 110-6.

7. Scott GL, Walton RE. Ultrasonics endodontics: the wear of instruments with usage. J Endod 1987; 12: 279-84.

8. Ahmad M. An analysis of breakage of ultrasonic files during root canal instrumentation. Endod Dent Traumatol 1990; 5: 78-82.

9. Ahmad M, Roy RA, Kamarudin AG, Safar M. The vibratory pattern of ultrasonic files driven piezoelectrically. Int Endo $f$ 1993; 2: 120-24.

10. Ahmad M, Pitt-Ford TR, Crum LA, Walton AJ. Ultrasonic debridement of canals: acoustic cavitation and its relevance. 7 Endod 1988; 14: 486-93.

11. Crum LA. Acoustic cavitation. In: Proceedings of the 1982 IEEE International Symposium on Sonics and Ultrasonics. San Diego, 1982; 1-12.

12. CRawford AE. The measurement of cavitation. Ultrasonic 1964; 2: 120-3

13. Flynn HG. Physics of acoustic cavitation in liquids. In: Mason WP, ed. Physical acoustics. New York: Academic Press, 1964; 57-172. 
This document is a scanned copy of a printed document. No warranty is given about the accuracy of the copy. Users should refer to the original published version of the material. 